\title{
The Role of Parents "Generation of Z" to the Early Children in the Using of Gadget
}

\author{
Felisitas Sihura \\ PGPAUD UAD Yogyakarta, Yogyakarta, Indonesia \\ e-mail: sr.felisitas@gmail.com
}

\begin{abstract}
Gadget is a modern communication which has many advanced functions. This tool is a small electronic device which has a variety of applications that simplify the way people communicate, looking for information, entertainment and do their hoby (game) with high work unit. Gadget gives a great impact on cultural values. Now, everyone around the world already have a gadget. users of this gadget is not only come from among workers but almost all kinds of people, including children and toddlers, who are already using gadget in their daily activities. In daily life, some people use their time on gadgets. Therefore, the gadget also has its own values and benefits for certain people. Some of the for examples are communication, business or gadget also have a negative impact for youth, children, and toddlers; which is addiction to gadget. This paper aim is to explain the role of parents in education their children for the use gadget. Therefore, it is a very important business affairs, looking for information, or just for entertainment. However, to understand the influences of gadget especially for parents, so that children know how to use gadget and parents can limit it's uses. Therfore the children can develop their talent well and become an active, intelligent, and interactive to others.
\end{abstract}

Keywords: Gadget, childhood, parents

\section{INTRODUCTION}

Digital children were born after the 1980s. Nowadays, all gadgets use to communicate, business affairs, to look for information, or just to get entertainment. However, there are many negative impacts that exist in the utilization of gadgets for teenagers, children, and even toddlers which are addiction. The usage of this gadget also requires special attention so that it does need to overdo it. It is known that "excessive" is a negative thing. The same things is when allowing children to be free for using their own gadgets without adult / parental guidance, which happens is a disturbance of mental and physical disrupted and even "addicted".

Growth and development of early childhood is also called the "Golden Age" or golden period, thus education of early childhood is a full concern for parents and for other educators. The presence of today's parents to accompany children is an important and urgent need. As parents, we do not only look at the negative effects of technological developments or gadgets that children use, but it also needs creative steps from parents in utilizing gadgets for the development of life and education of children. It is not easy to educate children, but the approachment is necessary. Parents are very central to educate children, because parents who know the habit children at home. Twenty-four hours, parents have to know the state of the child even though they are in school. The role of teachers is no less important, but teachers can only accompany and facilitate children to know the world in a good way. As a prospective educator, I am very concerned about seeing children to play with gadgets now, playing without seeing people directly. It is more individuals even less familiar with regional cultures. 
According Siswanto Igrea \& Lestari Sri (2012: 59) one of the characteristics of children is like imitating. Children like to imitate the habits of adults. The same thing is expressed by Bair Lupold Amy (2013: 10) "Childen from birth to preschool age typically experience technology in the arm of the parents through application on tablets or smartphones or time spent viewing television programming selected by their parents ". The parents should teach children good habits. Some children are quite obedient to do whatever their parents teach. However, most children will see the thing that has been taught is also obeyed by their parents. Other phenomena such as a family are sitting at a restaurant table, but there is not talking to each other. Each member is busy with gadgets on his hand, smiling to himself or talking to people who are not physically present. In a sense, they exist in togetherness in space and time, but their hearts are isolated. They do not look at each other, because each eye is staring at the gadget screen in front of them or engrossed themselves with the gadget.

Another fact is that parents often make the gadget as a babysitter, it means that when the child is crying, the parents give the gadget to the child so that his child calm and does not disturb his activity then given the gadget instead of him accompanying the child to play. Based on research conducted by The Asian Parent Insights in November 2014, 98 percent of 2,714 parents in Southeast Asia who followed the study allowed their children to access technology in the form of computers, smartphones, or tablets. This study was conducted on 2,714 parents in Southeast Asia who have children aged 3 8 years. The parents of these study participants came from Singapore, Malaysia, Thailand, Indonesia, and the Philippines. Based on the survey results, most parents allow their children to play gadgets for educational purposes. But in fact, according to survey results most of their sons and daughters use gadgets / tablets for entertainment purposes such as games (Unantenne, 2014: 10).

It needs proactive parental attitudes to embrace media guidelines and build assertive and media selection skills in children. It may happen if the parents first build a heart connection and willing to explore the child's media with them. The children listen to what thay have heard, watch what they are watching and play with them with the media they likes.

\section{LITERATURE REVIEW}

\subsection{Early Children}

The definition of early childhood proposed by National Assosiation Education For Young Childern (NAEYC) in Khasanah, Agung and Ellya (2011: 93) is "A group of individuals who are in the age range $0-8$ years." Or in the sense, early childhood is a group of people who are in the process of growth and development. At that age, experts named it the golden age (Golden Age) which occurs only once in the development of human life. In this period, the growth and development of early childhood needs to be directed to all aspects of development.

Aspects of development are MRV (Moral Religion Value) physical-motor, cognitive, socioemotional, language, and art. It will help the child in laying the right foundation for the formation of a whole person. In another meaning of early childhood, it assumes that early childhood has a wide range of age and understanding; it depends on the point of view used. Traditionally, the understanding of children is often defined as mini adult humans, who are still innocent and they are not been able to do anything or in other words they are not able to think. In addition, there is also another understanding that, early childhood is a small human who has the potential to be developed. According to Rahman (2002: 31) that "the experience experienced by children at an early age will have a strong effect on the next life" the experience will last long and it cannot be erased. If there is a stimulation that provoke life experience that ever experienced then the effect will reappear in a different form. Early children have characteristic characteristics both physically, socially, morally and so on. Childhood is also an age that is very important for all his life because the childhood of the foundation and basic personality that will determine the experience of children in the next life.

It can be understood that the early childhood, is a miniature adult who has the potential to grow and develop in him. Early child undergo the process of growth and development, not apart from the name of an adult as a helper.

\subsection{Gadget}

Gadget is a term derived from English, which means a small electronic device that has a special function. One of the things that differentiate gadgets 
with other electronic gadgets is always known as the element of "novelty". Nowadays, the gadget always comes up by presenting the latest technology that makes human life more practical. Jaka Irawan Leni Armawati (in Swarnadwitya, 2013: 4).

\subsection{Types of Gadgets}

Gadgets have a wide scope. Almost every small electronic device with special capabilities and present a new technology, it can be called a gadget. There are some types of gadgets that are often used, they are:

1. iPhone is a phone designed and marketed by Apple company and it has internet and multimedia connectivity

2. iPad is a tablet computer product made by Apple, has a form of display almost similar to iPod Touch and iPhone, only the size is larger than both the products and have additional functions such as those in the operating system.

3. Blackberry is a wireless handheld device that has the capability of e-mail service geges (push eemail), mobile phone, SMS, facsimile internet, surf the internet, and other wireless capabilities.

4. Xbox is the 6th generation video game console made by Microsoft and is the first video game console for Microsoft companies.

5. Netbook is a combination of portable computers between portable computers such as notebooks and the internet.

6. Mobile is an electronic telecommunication device that has the same basic capability as a fixed line conventional telephone, but can be carried anywhere (portable, mobile) and not connected to the telephone network using cable (wireless).

\subsection{Parents}

According to Anton Moeliono in KBBI (1989: 629) The word parent is a compound sentence, which lexically means "the father of the natural mother: the one who is considered old (clever, clever, expert and so on), the people who are respected. Based on the definition of etymology, the meaning of the parents referred to in this discussion is a person who has given birth and has a responsibility to children both children and children acquired through adoption. Jalaludin Rahmad (1993: 121)
Parents are the oldest, informal educational institutions, first and foremost experienced by children and educational institutions that are natural, parents are responsible to maintain, care, protect, and educate children to grow and develop properly. Binti Maunah (2009: 92). Zuhairini (1991: 177) reveals that the development of a child's life one of them is determined by the parent, then the parent's responsibility to the child is very important for the future of the child, because the first child grows and develops with the parents and according to the task of the parents in carrying out his role as an educational provider responsible for prioritizing the personal formation of children.

Based on the statement above, it is concluded that the parents are older people or elder people, but generally in society the parent's understanding is the person who has given birth to our mother and father, in addition to who has given birth to us this world. Mother and father also nurturing and guiding the child by providing good examples in living everyday life, besides the parents also introducing their children into the things that exist in this world and answer clearly about something that is not understood by the child, the knowledge the first received by the child is from his parents because the parents are the center of spiritual life and as a cause of his acquaintance with the outside, then every child's emotional reactions and thoughts in the future affected by his attitude towards the parents or mother and father plays an important and very important role affect the education of children.

\section{METHOD}

This type of writing in this paper is a literature study. The data obtained are presented descriptively, a source of literature in this paper from books, journals, and materials from the internet.

The technique used in data collection begins by collecting references that are relevant to the issues raised, namely the problems that exist in the field, especially The technique used in data collection begins by collecting references that are relevant to the issues raised, namely the problems that exist in the field, especially the role of parents "generation of $\mathrm{z}$ " to the early children in the using of gadget

After collecting the data, a literature review is carried out and then sorting out information that is relevant to the issues to be discussed. 
After the data is completed, then an analysis is carried out so that the results can be used in the discussion and formulated descriptively

\section{RESULT AND DISCUSSION}

\subsection{Negative and Positive Impact of Gadget}

Games contained in the gadget is now no longer the dominance of children. The adults are also fabulous manic game players, Family Libraries Teams (2006: 79). Therefore, the types of games are more diverse. Many kinds of Games have problem issue for parents in watching children using gadgets. Gadget is a modern communication tool that has many advanced functions. It is also defined as a small electronic device that has applications that make it easy for everyone who uses it to communicate, search for information, get entertainment and do hobbies (games) with high work units. Gadgets have a negative and positive impact on early childhood. It will be explained the positive and negative impacts below:

a. Positive Impact of Gadget

a) It can be a medium of learning to recognize colors, shapes and sounds

b) Giving a range of fine motor sensory by touching the screen.

c) Sharpening the child's brain when playing games that match his age

d) Increasing visual acuity

e) Improving language skills

f) Improving metatic abilities

b. Negative impact of Gadget

a) Inhibiting emotional intelligence

b) It risk of exposure to radiation

c) It neck pain and changes Anatomy of bone

d) It barriers to development

e) Slowing to understand the lesson

f) At risk for the development of child psychology

g) It changes in child behavior.

\subsection{Role of Parents}

Parents play a role in children's education to make young Generation domiciled. According to Abu Ahmadi in Eva Fahriantini (2016: 46), the explanation of parents in education, After a family is formed, the family members have their own duties. A work to be done in this family life is called as function. Therefore, family function is a job or a task to be done inside or outside the family. Parents are the primary educators and first educators for their children. They are in charge of the hereafter to the spiritual values, social values, skills and knowledge passed on to their children. Parents are also required to know the values obtained by their children in school related to the values taught in their household

Parents today are today's parents, not old parents or parents in the future. Parents today should also be able to develop technology in order to cultivate the values that exist in the use of gadgets. So it can help for behavioral, social and emotional development of children. According to Mubara Kayla, et al (2017: 97) Some parents are coming to the digital generation enthusiastically, some parents are frantic, worried, even almost paranoid because they only see the negative side of the gadget used.

According to Hurlock (1998: 82), parenting is a method of discipline that parents apply to their children. Parenting is a pattern of parental behavior applied to children that is relative and consistent from time to time. This pattern of behavior can be felt by the child in terms of negative and positive. Good parenting patterns can only be given by parents who really understand how to educate and nurture children properly, so as to stimulate all aspects of its development. Parenting pattern of the child there are three forms, among others: democratic parenting, authoritarian parenting and permissive parenting.

Parents need to avoid extreme attitudes in the form of rejection of all media reflected in several forms:

a) Teach children to avoid completely from the media by advising him to run from the media in their lives.

b) Separating children from all media is unrealistic

c) Choosing a medium for children who have aged, will make them untrained and do not have the power of selection

d) Authoritarian actions in the use of gadgets will only lead to rebellion in children

e) Indifference and indifference to the media will be read by the child as a message that it is harmless. 


\subsection{Steps to Reduce Gadget Impact Addiction}

The use of wise gadgets will certainly have a more positive impact on the development of children in its infancy. Thus, the use of gadgets is excessive and there is no control of the parents then the negative impact will be more as well. Parents play a vital role in accompanying children when using gadgets. If parents have successfully made a deal with a child about the rules of using gadgets such as making a schedule or determining the duration of time children can use gadgets and know what kind of games that children should play. This is a safe moment in using gadgets.

There are some steps that can be done by parents in assisting children who are addicted to gadgets namely:
a) Reducing play gradually
b) Encouraging children to socialize with peers
c) Making busy kids with a variety of interesting activities
d) Giving rewards
e) Be a parent as a role model
f) Setting free places to use gadgets
g) Spending time with the child

\section{CONCLUSION}

In the growth and development of children need so much help from their parents. The family is the basic foundation for the child to shape his personality, shape his mindset, and solve problems which is faced, even the influence of the school environment, the community environment and his family. However, parents are the main educators and especially for children. For parents, do not ignore the children. Parental control is important according to the proportion of children and not the proportion of adults because the child does not want to be restrained, when it happens then the child will show resistance. If it happens, than the parents will have difficulty in educating and parenting. Parents need to approach with children, discipline children in using the gadget as well as train children independence in managing the use of information technology or gadgets for positive and productive things. Thus, as time passes, as children enter adulthood they can also act as one member of society that spread the benefits of civilization.

\section{REFERENCES}

[1] Fahriantini Eva. (2016). The Role of Parents In Child Control On The Use Of Blackberry Messenger In Al Azhar Syifa Budi Samarinda: Communication Science. 4 (4), 44-55. (Accessed July 15, 2018)

[2] Family Familia Team, (2006). Dismissed Barriers Child Growth. Yogyakarta: Kanisius

[3] Hurlock B. Elizabeth, (1998). Child Development Volume I. Jakarta: Erlangga

[4] Igrea Siswanto \& Sri Lestari. (2012) Guide for Teachers and Parents of Attractive Learning and 100 Creative Lands for PAUD. Yogyakarta: ANDI

[5] Jaka Irawan Leni Armawati Swarnadwitya. (2013). The Influence of the Use of Gadget on Socializing Ability in Youth, An- Nafs, Vol. 08, No. $\quad 02$, Th 2013. http://jurnal.uir.ac.id/index.php/JAN/article/vie wFile/422/359 Accessed July 20, 2018

[6] Jalaludin Rahmad (1993) Islami Alternatif Lectures on campus Bandung: Mizan

[7] Khasanah, Ismatul Agung Prasetio, Ellya Rahmawati. 2015. Traditional Games As A Media Stimulation Aspects of Early Childhood Development. Journal PAUDIA Research. Vol 1. No.1

[8] Murbara Kayla et al. (2017). Smartmom for Smart Generation. Yogyakarta: DIVA Press

[9] Rahman Hibana S (2005). Basic Concepts of Early Childhood Education. Yogyakarta. Grafindo Litera Media.

[10] Unantenne, N. (2014). Mobile Device Usage Among Young Kids: A Southeast Asia Study. The Asian Parent Insight. Retrieved from:https://s3-ap-

southeast1.amazonaws.com/tapsgmedia/theAsia nparent+Insights+Device+Usage+A+Southeast + Asia+Study + November +2014 . (accessed, Sunday, July 08, 2018)

[11] Zuhairini. (1991) Islamic Education Philosophy. Jakarta: Earth Literacy 